\title{
A paradigmatic disagreement in "Dialogue on Dialogic Pedagogy" by Eugene Matusov and Kiyotaka Miyazaki
}

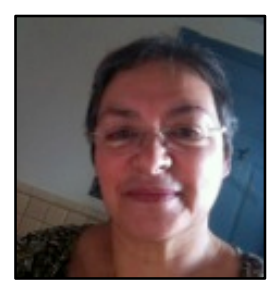

Ana Marjanovic-Shane

Chestnut Hill College, USA

\begin{abstract}
I read with a great pleasure the heated dialogue on Dialogic Pedagogy between Eugene Matusov and Kiyotaka Miyazaki. It provided me with one of those rare occasions where I could both witness, and also join, the workings of two minds as they struggled with and against each other to construct, de-construct, and reconstruct their visions of dialogic pedagogical approaches to education. As I was reading, I had a lot of questions and remarks. I try to summarize them here - while many are still left on the margins of the original manuscript.
\end{abstract}

Let me first explain the way that I have framed my response. First of all, from now on, I will address you, Eugene and Kiyo, directly, instead of addressing your concepts impersonally and talking about you in the third person. Using first person will set the tone of my dialogue with the two of you, together or separately, and will help me introduce some of my questions, ideas, and perspectives in a more dialogic fashion. Second, my current understanding of, and position on, the issues are closer to yours, Eugene, than yours, Kiyo. Thus, my views are biased, yet they are based on my own "internally persuasive discourse" (Bakhtin, 1991). On the other hand, I arrived at my current position by going through many transformations, starting out with views that were relatively more similar to yours, Kiyo. And, the road I have traveled on this journey is still fresh in my mind. Thus, I think I recognize at least some of your perspectives, Kiyo, with a nod of the head, despite my current critique. Third, I will discuss here only a few issues that stand out for me from your dialogue, without describing all parts of the debate, as I assume that readers are already familiar with your debate.

My discussion includes a summary of the two paradigms you develop, their boundaries, and the wonderful examples you shared to support your arguments. I also discuss the struggles between Eugene's and Kiyo's paradigms that I see as bridgeable and not bridgeable.

\section{No shared boundaries}

First of all, it is obvious that the two of you conceptualize very differently the vital notions of this discussion: the "epistemological," "ontological," "instrumental," "dialogic," and "monologic." I want to point out, that I see your conceptualizations as NOT sharing boundaries. Instead, you are each engaged in 


\section{A paradigmatic disagreement in "Dialogue on dialogic pedagogy"}

Ana Marjanovic-Shane

creating a paradigmatically different, internally systematic perspective. In his book, The Structure of Scientific Revolutions, Thomas Kuhn writes, "What differentiated these various schools was not one or another failure of method: they were all 'scientific' - but what we shall come to call their incommensurable ways of seeing the world and of practicing science in it" (Kuhn, 1996, p. 4). I will try to discuss some of the major points of your paradigmatic disagreement that make your positions "incommensurable", i.e. not sharing boundaries, but still providing enough tension that makes each position sharply delineated against the background of the other.

Let me start with the notion of "epistemological."

Eugene, I see your use of the term "epistemology" and "epistemological" as potentially polysemic. When you use the term "epistemology/epistemological" it seems that you actually refer to two different concepts depending on the particular context. On one hand, when contrasted to "ontology," "epistemology" is about the "ways of knowing" in general, while "ontology" is about the "ways of being". Thus, in this use, "epistemology" is a very general concept of all "ways of knowing" in contrast to the "ways of being." Seen that way, epistemology and ontology are two distinct aspects of the human life. Distinct, but seen as necessarily connected, inter-related, having effect on each other. In other words, possibly even "two sides of the same coin." I think that this is what you, Kiyo, have in mind when you discuss the interrelatedness of the two.

On the other hand, however, you use the term "epistemological" to refer to one of the four ways knowing described by Aristotle (2000): techne, epistêmê, phronêsis and sophia. In this sense, you use the concept of "epistêmê" for a very specific type of knowing and a very specific kind of knowledge. Using it in this way, you inevitably also include and imply specific beliefs about the value of that way of knowing, describing it as "epistemological positivism" where it is assumed that "epistêmê" is universal, impersonal, ahistorical, decontextualized, objective, universally true, of a higher order than any personal, subjective, local, limited, even biased point of view. For instance, you say,

Elsewhere I argued (Matusov, 2009a, ch. 2) that Plato's Socratic Dialogic Method is a bizarre combination of radical pedagogical constructivism, based on dialogic investigation of truth though revealing contradictions in people's thinking, and radical philosophical positivism, based on the preset curricular endpoints reflecting the eternal, universal ideas (page 8).

Eugene, you move between the two meanings of this concept very easily and smoothly, but without explanation, and I think that the way you switch from one to another may potentially create confusion.

I think, Kiyo, that you use the concept of "epistemological" in the first, more general way, in contrast with "ontological." It seems that this general meaning absorbs other potential meanings like an "umbrella" concept. From that point of view (as I pointed out above) the interrelatedness between the "being" (ontology) and the "knowing" (epistemology), is crucial to stress. Your insistence regarding the interconnectedness between the epistemological and ontological is wonderfully illustrated in your example of Yukio Tsukamoto's search for meaning in a Japanese poem about a butterfly, a meaning that he can connect to his own life, thereby simultaneously pursuing epistemological understanding and ontological relevance. Thus, from your point of view, it may seem unreasonable when Eugene discusses a sharp contrast between ontological and epistemological pedagogy. It seems to me that you see the boundary between them as "bridgeable" because the two aspects of human life (ontology and epistemology) are interrelated and it should always be possible to find a connection. 


\section{A paradigmatic disagreement in "Dialogue on dialogic pedagogy"}

Ana Marjanovic-Shane

However, it also seems to me, Kiyo, that the Gibsonian analogy mapping "perception-action loop" on the epistemological-ontological relationship is a trap for your way of conceptualizing this relationship. The "perception-action" loop comes from reductionist theories and research - that attempt to reduce allliving beings to a mechanical type of functioning, describable by the flow of neurological currents. In my view, there is no way to connect the theory that humans develop via the mechanics of "perception-action" with an acknowledgment that being and knowing is ontological. Having said that, Kiyo, I still see your disagreement with Eugene's sharp contrast between the epistemological (I and II) and the ontological as your way of insisting on the relevance of the Aristotelian "epistêmê" - a generic, universalist, concept of "knowing", for the "being."

The second important concept in your dialogue is the concept of instrumentality. The two of you conceptualize "instrumental" in two different ways, and furthermore, this concept plays different roles in supporting your two contrasting views. For you, Eugene, it is important to make a distinction between the instrumental and non-instrumental dialogue, because it describes the ultimate power relationship between the teacher and the student. When a teacher uses dialogue as an instrument to achieve certain pedagogical goals, the teacher "highjacks" the very human need to participate in an internally persuasive discourse. In this way, teachers then manipulate the dialogue to stir it toward his/her preset curricular endpoints; potentially, even to send someone on the teacher pre-conceived curricular journey (as in predominantly responsive authorship). Eugene, you say that the instrumental epistemological pedagogy is

\footnotetext{
... characterized by the use of dialogue between the teacher and the students and among the students to achieve some particular intellectual curricular endpoints preset by the teacher. Dialogue here is a pedagogical method. ... Thus, the epistemological instrumental pedagogy is primary concerned with deepening students' intellectual understanding about something but this deepening has some curricular endpoints (p. 7).
}

However, Kiyo, for you, Eugene's distinction between epistemological instrumental and epistemological non-instrumental pedagogies does not make much sense. You say: "Though Eugene divides epistemological pedagogy to instrumental and non-instrumental, I do not distinguish these two here" (p. 20). I think that the reason you do not see such a distinction as important, is a result of two related aspects of your conceptualizations. I will try to revoice them here, but please, correct me if I am wrong.

First, you, Kiyo, are mainly focused on Eugene's distinction between the epistemological and ontological dialogues - where you conceptualize "epistemological" in its more generic sense. Thus, you are trying to solve this epistemology-ontology relationship, rather than address the two types of epistemological dialogues described by Eugene.

Second, it seems to me, Kiyo, that for you, the crucial difference between the two types of dialogues, (epistemological and ontological), is in their content, i.e. spheres of knowing: high culture or mundane life, and how these spheres of knowing are related. It seems that you are trying to conceptualize the connection between the epistemological dialogue (about high culture, or socially valued content) and the ontological dialogue (about the mundane life of a person) - in a way that is noninstrumental, but rather more intrinsically interrelated - or at least that it can be pedagogically achieved such as through your beautiful example of the butterfly poem.

However, I think that "instrumentality" for you, Eugene, is not about the content of dialogue. It is not about whether an intellectual (epistemological) content of a dialogue can "serve" student's ontological 


\section{A paradigmatic disagreement in "Dialogue on dialogic pedagogy"}

Ana Marjanovic-Shane

needs, interests and desires, or not. Instead, I interpret your notion of "instrumentality" of an epistemological dialogue, as a defining characteristic of the power relationships between the participants. In other words, if the teacher's goal is that students arrive at some (any) preset curricular endpoints, then any dialogue (regardless of its content) is an instrument of that goal. In my view, Eugene, your distinction between instrumental and non-instrumental epistemological dialogue is in the teacher's use of his or her power to impose certain pre-determined, universal truths by manipulating dialogue - as you described in the four steps of Socratic dialogue. On the other hand, what you call non-instrumental epistemological dialogue does not impose final "truths" (a.k.a. philosophical positivism), yet it does impose "final" values, for example, what is considered to be universally (or at least culturally and socially) valuable in its dealing with the highest questions about human existence. Thus, instrumental epistemological dialogue is about (correct) answers (truths), and the non-instrumental epistemological dialogue is about the (right) choice of questions to consider. I think that you, Kiyo, has sensed this aspect of Eugene's views in your analysis of a teacher stimulating her own and children's intellectual curiosity and creating connections between the participant's life and the culturally valuable intellectual content. However, Kiyo, it seems to me that because you focus on the content of the epistemological and ontological dialogues, you must prioritize the culturally valuable (high) content, and you emphasize not merely the possibility, but also the need and value of making the connections between the two (epistemological and ontological contents). Because of your view, I do not think you see any relevancy in distinguishing the instrumentality of dialogue.

However, what Eugene criticizes is not the content of epistemological inquiries, but the power relationship between the participants in which the teacher's agency, authorship, interests, and beliefs dominate and eclipse students' agency, authorship, interests, and beliefs. In the epistemological noninstrumental dialogue, described by Eugene, I see the teacher's monologism NOT in the teacher's use of the dialogue BUT in the teacher's subordination of students' ontology to universal truths (epistêmê) and the (high) cultural axiology (i.e., a system of values) that are prioritized.

The real point of departure between your two views becomes palpably sharp during your discussion of teacher-student relationships. It seems to me, Kiyo, that your vision of a teacher as a dialogic author of students' education is motivated by your view of dialogue as the primary mode of the learners' transformation and, at the same time, your belief in the priority of the known epistemological truths and cultural values. Because of that, learners' agency in your understanding, their ontological needs, interests, ways of relating to others and the world, immediate life events cannot be left without guidance; students cannot drive their learning journey. Learners' agency, according to your view, Kiyo, must be encompassed within the teacher's authorial dialogic teaching. You see students' agency only as developing during dialogues with the teacher, and you criticize Eugene's distinction of the responsive and self-generated agency. For instance, you, Kiyo, share,

I do not think that the learner, or the human being in general, has two types of the authorship, or agency. Human being is an agent by nature. In the sense that no one can put agency into some other, agency of human being is self-generated. Simultaneously, agency in human being grows up by interacting with other people. The learner can enter into the dialogic lesson and act as the dialogic heroine/hero because she/he is originally an agent. Her/his experience of being the dialogic heroine/hero in the dialogic lesson helps her/his agency grow up (p. 41).

What Eugene describes as a possibility that a learner takes over the navigation and the driving of his/her agency in a case of self-generated learning journey, seems inconceivable and anti-educational from your point of view, Kiyo. As you say, "The learners who can leave the lesson by themselves and ask

Dialogic Pedagogy: An International Online Journal | http://dpj.pitt.edu DOI: 10.5195/dpj.2014.122 | Vol. 2 (2014) 
the 'teacher's' help will no longer need someone who tries to have the pedagogical relationship with them. They will be able to make use of anyone to get some help she/he needs when necessary. So, she/he does not need 'the teacher', much less 'the pedagogy'. Then, why do you need pedagogy? (p. 42)"

On that note, Eugene, Kiyo's questions have legitimacy. If learning is only about the learners, then what is the role of the educators? Your conception of pedagogy, Eugene, from Kiyo's point of view looks incommensurable, potentially needless, almost pointless.

And from Eugene's point of view, Kiyo, your insistence that the teacher needs to retain the epistemological authority, and with it potentially other kinds of authority: legal, moral, and agentive, seems also to be a legitimate objection, since it is incommensurable with a dialogicity as a meeting of people with equal rights (cf. Bakhtin, 1999).

This is why, Kiyo and Eugene, I see your arguments as not simply opposed to each other on the same continuum, but rather, as being on two incompatible planes: they are from two different paradigms. I have to stress that paradigmatic boundaries are not boundaries "between" two paradigms, as some kind of a border that provides a line separating their territories. Paradigmatic boundaries are not like the cultural boundaries where the cultures are constructed in the contrasting light of the other cultures. Paradigmatic differences create no "touch" between the two - and from the point of view of each one, the other one is disorienting and looks potentially like nonsense. Here is my first and not completed attempt to sketch a comparison between your two paradigms.

Table 1: Two Paradigms of Dialogic Pedagogy

\begin{tabular}{|l|l|l|}
\hline & $\begin{array}{l}\text { Epistemological Non- } \\
\text { Instrumental Dialogic } \\
\text { Pedagogy Paradigm (Kiyo) }\end{array}$ & $\begin{array}{l}\text { Ontological Dialogic Pedagogy } \\
\text { paradigm (Eugene) }\end{array}$ \\
\hline Focus of the scholarship & $\begin{array}{l}\text { Examining the universal, } \\
\text { essential principles of the } \\
\text { dialogic approach to education. }\end{array}$ & $\begin{array}{l}\text { Examining the views of the participants } \\
\text { in dialogic approaches to education } \\
\text { about their own praxis, their } \\
\text { motivations, values, ways to relate to } \\
\text { others, addressivity, power relations, } \\
\text { and so on. }\end{array}$ \\
\hline $\begin{array}{l}\text { Purpose of pedagogy } \\
\text { (education) }\end{array}$ & $\begin{array}{l}\text { Connecting the learner's whole } \\
\text { being with the socially, culturally, } \\
\text { and universally valuable contents } \\
\text { of knowledge to enrich their life } \\
\text { and develop their ideas. }\end{array}$ & $\begin{array}{l}\text { Helping the learners in their own critical } \\
\text { examination of their own living and } \\
\text { evolving positions, testing their ideas } \\
\text { regarding the values, purposes, } \\
\text { interests, goals and journeys they want } \\
\text { to undertake. }\end{array}$ \\
\hline
\end{tabular}




\begin{tabular}{|c|c|c|}
\hline $\begin{array}{l}\text { Espoused conception of } \\
\text { a "good" pedagogical } \\
\text { approach }\end{array}$ & $\begin{array}{l}\text { Pedagogy is seen as praxis - a } \\
\text { practice that evolves in } \\
\text { unpredictable ways based on the } \\
\text { (self) evaluations (by teachers) - } \\
\text { of guiding learners' development } \\
\text { through promoting and arranging } \\
\text { opportunities for the learners to } \\
\text { participate in important } \\
\text { dialogues, following rich, ill- } \\
\text { defined and unpredictable } \\
\text { process that will engage them } \\
\text { with culturally and socially valued } \\
\text { knowledge and practices. }\end{array}$ & $\begin{array}{l}\text { Pedagogy is seen as praxis of praxis - } \\
\text { a "critical evaluation and } \\
\text { problematizations of ready-made of } \\
\text { culture" (Matusov \& Marjanovic-Shane, } \\
\text { 2012) and of the very praxis of teaching } \\
\text { and learning by all the participants; } \\
\text { promoting learners' authorial stance } \\
\text { toward their own learning and } \\
\text { development by providing dialogic } \\
\text { opportunities for testing ideas, desires, } \\
\text { values, motivations, opinions; and } \\
\text { promoting learners' self-generated } \\
\text { learning journeys. }\end{array}$ \\
\hline $\begin{array}{l}\text { Powers of authority of } \\
\text { the teacher and the } \\
\text { student }\end{array}$ & $\begin{array}{l}\text { Teacher has both } \\
\text { epistemological and ontological } \\
\text { authority over his/her students. } \\
\text { Teacher as author and student } \\
\text { as hero. Learners' agency must } \\
\text { be encompassed by the } \\
\text { teacher's authorial dialogic } \\
\text { teaching, which is the source of } \\
\text { guidance and growth of student's } \\
\text { agency. }\end{array}$ & $\begin{array}{l}\text { Teacher has limited epistemological } \\
\text { authority (as a good consultant or a } \\
\text { tour guide when asked for help by the } \\
\text { student); but the student has } \\
\text { ontological authority and } \\
\text { epistemological authority: i.e. the } \\
\text { student is the final author of his/her } \\
\text { learning and life. }\end{array}$ \\
\hline $\begin{array}{l}\text { Characterization of the } \\
\text { type of Dialogic } \\
\text { Pedagogy using } \\
\text { Eugene's classification }\end{array}$ & $\begin{array}{l}\text { Epistemological non-instrumental } \\
\text { dialogic pedagogy }\end{array}$ & $\begin{array}{l}\text { Ontological dialogic pedagogy seen as } \\
\text { promoting praxis of praxis. }\end{array}$ \\
\hline $\begin{array}{l}\text { Characterization of the } \\
\text { type of Dialogic } \\
\text { Pedagogy using Kiyo's } \\
\text { conceptualization }\end{array}$ & $\begin{array}{l}\text { Authorial creating of dialogic (as } \\
\text { opposed to monologic) "lessons" } \\
\text { by the teacher who examines } \\
\text { and finds new and exciting } \\
\text { perspectives to entice and guide } \\
\text { the students' dialogic } \\
\text { participation in learning. }\end{array}$ & $\begin{array}{l}\text { Potentially a self- destructive endeavor } \\
\text { when promoting students' self- } \\
\text { generated authorship that may be in } \\
\text { opposition to the students' responsive } \\
\text { authorial learning, since "The learners } \\
\text { who can leave the lesson by } \\
\text { themselves and ask the "teacher's" } \\
\text { help will no longer need someone who } \\
\text { tries to have the pedagogical } \\
\text { relationship with them." }\end{array}$ \\
\hline
\end{tabular}




\section{Instead of a conclusion}

Dear Eugene and Kiyo,

I have learned a lot form both of you in this wonderful dialogue on dialogic pedagogy. I thank you both!

There is no conclusion! I think we are all in a process of dialogic change. I see things with different eyes today than I saw them yesterday. And I am even more puzzled now!

Ana

\section{References}

Aristotle. (2000). Nicomachean ethics (R. Crisp, Trans.). Cambridge, UK: Cambridge University Press.

Bakhtin, M. M. (1991). Dialogic imagination: Four essays (C. Emerson \& M. Holquist, Trans.). Austin, TX: University of Texas Press.

Bakhtin, M. M. (1999). Problems of Dostoevsky's poetics (C. Emerson, Trans.). Minneapolis: University of Minnesota Press.

Kuhn, T. S. (1996). The structure of scientific revolutions. Chicago, IL: University of Chicago Press.

Matusov, E., \& Marjanovic-Shane, A. (2012). Diverse Approaches to Education: Alienated Learning, Closed and Open Participatory Socialization, and Critical Dialogue. Human Development, 55, 159-166. doi: 10.1159/000339594

\section{(c)) EY}

New articles in this journal are licensed under a Creative Commons Attribution 4.0 United States License.

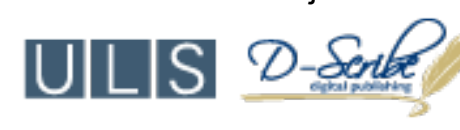

This journal is published by the University Library System, University of Pittsburgh as part of its D-Scribe Digital Publishing Program and is cosponsored by the University of Pittsburgh Press. 